\title{
BAMBI: neues Zielmolekül für die Therapie
}

Nicht-kleinzelliger Lungenkrebs (NSCLC) metastasiert oftmals früh und geht aufgrund fehlender Behandlungsmöglichkeiten mit einer hohen Sterberate einher. Wissenschaftlern des Deutschen Zentrums für Lungenforschung (DZL) ist es nun gelungen, mit BAMBI ein Protein zu identifizieren, dessen Regulation zu diesen Eigenschaften beiträgt. Ihre Ergebnisse zu BAMBI und dessen Zusammenspiel mit dem sog. TGF- $\beta$-Signalweg sind im Mai in Cancer Research (DOI 10.1158/00085472.CAN-15-1326) erschienen.

Das körpereigene Protein TGF- $\beta$ (Transforming Growth Factor $\beta$ ) hat gegensätzliche Wirkungen in verschiedenen Stadien einer Lungenkrebserkrankung: In der frühen Phase wird die Entwicklung von Krebszellen gehemmt, indem maligne Zellen durch programmierten Zelltod abgetötet werden. In späteren Stadien fördert der TGF- $\beta$ Signalweg dagegen Invasivität und Metastasierung. In der nun publizierten Studie wurde an Gewebeproben fortgeschrittener Tumore gezeigt, dass beim NSCLC entscheidende Moleküle des TGF- $\beta$-Signalwegs aktiviert sind. Das bedeutet, dass TGF- $\beta$ vermehrt an seinen Rezeptor an der Zelloberfläche bindet und dadurch eine Signalkaskade im Inneren der Zelle auslöst. Auf diese Weise wird eine ganze Reihe von Zielgenen des TGF- $\beta$-Signalwegs aktiviert, wodurch letztlich die Metastasierungsfähigkeit der Zelle steigt.

Auffälligerweise kommt gleichzeitig ein anderes Zelloberflächenprotein, das sog. BAMBI, in Lungentumorgeweben seltener vor. BAMBI ist Teil eines Pseudorezeptors, der kein Signal in die Zelle weiterleitet. Der funktionelle TGF- $\beta$-Rezeptor konkurriert mit dem BAMBI-Pseudorezeptor um die Bindung von TGF- $\beta$. Je weniger BAMBI-Protein sich also auf der Zelloberfläche befindet, desto mehr Signal wird über den funktionellen TGF- $\beta$-Rezeptor in die Zelle weitergeleitet. BAMBI ist somit ein negativer
Regulator des TGF- $\beta$-Signalwegs. „Durch die verminderte Bildung von BAMBI steigert der Tumor seine Bösartigkeit“, kommentiert Dr. S. Marwitz, Borstel, die experimentellen Ergebnisse. Der Grund für die verminderte Bildung: Der Promotor des BAMBI-Gens weist in Tumorzellen eine stärkere DNA-Methylierung auf, wodurch das Gen stillgeschaltet wird.

Weitere Versuche sollten klären, was passiert, wenn man die Tumorzellen so beeinflusst, dass sie wieder BAMBI-Protein produzieren. Verlieren sie dadurch ihre malignen Eigenschaften? In der Tat verhalten sich die so manipulierten Zellen weniger invasiv. „Diese Ergebnisse zeigen die Bedeutung von quantitativen, zeitaufgelösten Untersuchungen für die Entschlüsselung von molekularen Mechanismen, die zur Krebsprogression beitragen können“, sagt Prof. U. Klingmüller, Heidelberg. Die Ergebnisse würden zeigen, dass die Blockierung des TGF- $\beta$-Signalwegs eine neue Option zur Behandlung von nicht-kleinzelligem Lungenkrebs sei.

Nach einer Mitteilung des Deutschen Zentrums für Lungenforschung e.V. 